\title{
Best Practices for an Equitable Clean Energy Transition: A Toolkit for U.S. States
}

\author{
$\underline{\text { Sindhu S. Nathan }}^{1}, \underline{\text { Kavitha Chintam }}^{2}$, Brooks Clingman ${ }^{3}$, \\ Alexandra Johnson ${ }^{4}$
}

\author{
${ }^{1}$ Stanford University, Department of Chemical Engineering, Stanford, CA \\ ${ }^{2}$ Northwestern University, Department of Chemical and Biological Engineering, Evanston, IL \\ ${ }^{3}$ Massachusetts Institute of Technology, Department of Materials Science and Engineering, Cambridge, MA \\ ${ }^{4}$ University of California, Berkeley, Department of Public Health, Berkeley, CA \\ https://doi.org/10.38126/ISPG180208 \\ Corresponding Author: sindhu.s.nathan@gmail.com \\ Keywords: clean energy; energy equity; U.S. state policies; climate change
}

\begin{abstract}
Executive Summary: The clean energy transition is underway, providing valuable insights for governments introducing clean energy policies. However, not all policies are equal, and some communities are excluded from the benefits of the energy transition without policies that explicitly involve them. These excluded people are members of environmental justice communities, people from low-income communities, and others who have been historically discriminated against. We propose a "clean energy equity toolkit" to promote an equitable transition for U.S. state governments presented to the leadership of the National Governors Association, where state governments share best practices. This toolkit identifies policies that help more people reap lower electricity costs, gain access to clean energy jobs, and realize other benefits like improved air quality. We recommend three policies: (1) establish a Clean Energy Equity Office, (2) develop a Clean Energy Career Advancement Program, and (3) implement a minimum resource investment requirement for clean energy projects benefiting disadvantaged communities. Though this toolkit is directed to U.S. state governments, the policies can be adapted by other interested parties and states, domestic and international.
\end{abstract}

\section{Statement of issue}

The transition from fossil fuels to clean energy is urgent in order to mitigate the consequences of global warming including sea level rise, elevated temperatures, drought, and biodiversity loss (Zhai et al. 2018). Initial clean energy policies incentivized early adopters, resulting in technology deployment clustered in wealthier, white neighborhoods (Kann and Toth 2017). However, energy equity should not be ignored for the sake of expediency. Energy equity refers to the fair distribution of energy benefits (e.g., new technologies, jobs, economic, health and environmental benefits) and burdens (e.g., lost jobs, disruptions to local economies, noise disruptions, and loss of fossil-fuel community identity) across communities (Carley and Konisky 2020). Policies must prevent the clean energy transition from unfairly providing benefits to select communities.
Disadvantaged communities (DACs) include lowincome, and Black, Indigenous, and people of color communities. Also included are environmental justice communities, who have historically not been adequately protected from environmental and health hazards and have lacked equal access to decision making processes related to those hazards (EPA 2016). These communities often do not receive the full benefits of clean energy due to programmatic flaws in existing government programs aiming to benefit DACs. These flaws, in turn, exacerbate two additional challenges DACs face: lower access to high quality jobs and lower likelihood to participate in clean energy programs (CPUC, n.d.a; Carley and Konisky 2020). Each shortcoming poses a challenge for achieving energy equity. 
Programmatic flaws at the United States (U.S.) state level include varied eligibility guidelines which excludes some vulnerable populations. For example, California's Self-Generation Incentive Program included a $25 \%$ carve-out for DACs, defined using data from CalEnviroScreen (CPUC, n.d.a; CPUC, n.d.b). However, the original definition excluded applicants on Tribal lands despite the fact that these communities experience poor electrical service reliability that warrant these additional benefits (CPUC 2019). The program also had a burdensome application process and lacked outreach to communities, resulting in little participation from members of DACs (Mullendore 2019).

Diversity in the clean energy workforce is concentrated in the lowest paying installation jobs while leadership roles are dominated by white workers. For example, 28\% of New Jersey workers in the four largest solar job categories (e.g. installation) were people of color (Vachon 2019). In contrast, 88\% of executives in the U.S. solar industry are white as of 2020 (Foster 2020), and 78\% of the nation's energy efficiency workforce, ranging from installation to managerial positions, is white. The limited diversity of employees in higher-paying clean energy roles also limits the socioeconomic mobility of members of DACs (Berube 2019).

Finally, a combination of factors including racism, lack of disposable income, and lack of homeownership can make members of DACs less likely to participate in clean energy programs. These burdens may become increasingly concentrated within DACs while the benefits of clean energy are distributed elsewhere. (Lukanov and Krieger 2019). For example, communities with greater diversity or lower median incomes are slower and less likely to participate in government-subsidized distributed solar programs (Griffith, Higgins and Turner 2014; Lukanov and Krieger 2019). Additionally, majority Black and Hispanic (as defined by the source) communities are $69 \%$ and $30 \%$, respectively, less likely to adopt rooftop solar than no-majority communities, even after accounting for differences in income and homeownership. Conversely, majoritywhite communities are $21 \%$ more likely to adopt rooftop solar (Sunter, Castellanos, and Kammen 2019). These trends are despite the fact that communities of color are more likely to support policies aimed at addressing climate change and will adopt clean energy technologies at a faster rate when policies support this interest (Langer 2018; CPUC 2021; Sunter, Castellanos and Kammen 2019).

Although several U.S. states have enacted progressive policies to promote an equitable energy transition (Table A1, Table A2), this process has been slow, and many other states have yet to take action. Recognizing the opportunity to remediate this policy gap, we propose a "clean energy equity toolkit" composed of three recommendations. These policies are grounded in state-level best practices and serve as a blueprint for other U.S. states to enact equitable energy policies. We direct this toolkit to the Chair and Vice-Chair of the National Governors Association (NGA), where state best practices documents are made available to individual governments. The NGA comprises all U.S. states and strives to maintain nonpartisanship when approaching all policy issues, including the climate crisis, allowing every state to benefit from climate-related toolkits the NGA disseminates. Documents at the NGA are publicly accessible and thus are also useful resources for interested parties and states outside of the U.S.

\section{Policy options}

i. Recommendation 1: Establish a state-level Clean Energy Equity Office (CEEO) to promote and assess clean energy investments in DACs

We recommend state governments establish a centralized Clean Energy Equity Office (CEEO) adapted from New Jersey's (N) proposed Office of Clean Energy Equity, to ensure that equity is a focal point of the clean energy transition (New Jersey Legislature 2020). The NJ Office is designed to oversee many aspects of the equitable distribution of clean energy and sustainability programs including job opportunities, technologies, and infrastructure. Inspired by the NJ office, we recommend two roles for future state CEEOs: (1) community outreach and program planning and (2) program assessment. This CEEO will use data collected from local efforts and program assessments to make state clean energy program policy recommendations to the legislature.

CEEO outreach to local governments and community organizations will help the state identify DACs and determine what energy needs require funding. Identifying these communities and needs will designate programs to help members of DACs 
directly access clean energy benefits. The efficacy of community outreach prior to program development is demonstrated in Long Beach, California, where developers' understanding that DACs experience disproportionate exposure to pollution led to pilot projects aimed at improving air quality for these communities (Ayub 2020). Furthermore, targeted outreach increases the likelihood that projects will be accepted and adopted by communities, strengthens local networks, and increases public trust (Penn State, n.d.). For example, by starting a "Building Performance with ENERGY STAR" program to engage schools and community groups in energy efficiency initiatives, Michigan utility Consumer Energy demonstrates the outreach we propose a CEEO perform. Consumer Energy assisted each participating district to benchmark its buildings, provided an energy assessment for one of the poorest performing buildings in each district, worked with school officials to develop energy savings goals and an energy management plan, and designed a roadmap to achieve an overall reduction in energy use district-wide (ENERGY STAR 2020).

Impact assessments based on predetermined and comprehensive metrics will evaluate where state resources have been allocated and what benefits have been realized by DACs. This strategy was implemented in the Environmental Protection Agency's Chumash Community Energy Efficiency and Renewable Energy Project (CCEP) in Santa Barbara County, California. The CCEP demonstrated successful solar deployment to members of the Santa Ynez Chumash tribe by measuring carbon emissions saved by solar panels installed, tracking the number of buildings that participated in energy audits, and determining the number of Tribal members who held clean energy jobs (EPA 2016). The CEEO has the means to use this type of data to standardize metrics between programs and ensure that programs are held accountable by making these assessments publicly accessible.

CEEO implementation in populous states may face higher administrative burdens and costs. These challenges can be mitigated by emulating NJ's proposed policy, which caps administrative costs at $10 \%$ of the program's budget (New Jersey Legislature 2020). A percentage cap on these costs enables states to increase spending to meet program demands while keeping relative spending low.
Some states' existing clean energy programs may have equity components or responsibilities that overlap with the role a CEEO could fulfill. Thus, we emphasize outreach and assessment as the two key roles that this office could adopt that would support programs that run out of any agency in the state's government. The emphasis on each role may vary depending upon the state's unique needs and any existing programs. This would allow for the differentiation between current offices and a CEEO dedicated to equity and access. Achieving a more equitable energy future requires focusing on proper program planning, implementation, and assessment.

ii. Recommendation 2: Develop a Clean Energy Career Advancement Program (CECAP) to incentivize companies to diversify their workforces and fund clean energy apprenticeship programs

We recommend developing a Clean Energy Career Advancement Program (CECAP) to address workforce inequalities and provide training and job opportunities to DACs. This program leverages the strengths of bills and initiatives across the U.S. (Table A1). The CECAP will include: (1) subsidies for stateapproved, privately funded apprenticeship programs, (2) tax incentives for companies that demonstrate a diverse workforce, and (3) incentives for companies to build relationships with local institutions to integrate the community in the clean energy transition. The CECAP will also serve members of the existing fossil-fuel energy workforce whose jobs may be redistributed as communities transition to clean energy.

State-approved apprenticeship programs that prioritize training people from DACs and allow local workers to start at levels based on their experience, skills, and prior education will generate a diverse energy workforce (Luke 2017). There is a precedent for these programs; apprenticeships are already common in trades like ironworking. The CECAP will provide guidelines for companies that encourage upward socioeconomic mobility through paths for promotions. As workers move from installation jobs to higher-paying roles, new workers in clean energy can take on those vacated roles. This policy option also centers communities in the clean energy transition, which will allow for more equitable practices due to a diverse range of perspectives. 
It is critical to continuously assess the clean energy workforce to confirm that training and employment opportunities are equitably distributed. We recommend that the CECAP is assessed annually using workforce demographics like self-identified identities (i.e., race, gender, and sexual identity), incomes, length of employment, and geographic distribution of the workforce. Demographics will be compared to state census data and other records to track changes in the clean energy workforce and measure the efficacy of CECAP. Consistent tracking and data-driven programming will support equitable job distribution and promote transparency.

There is a risk that funding for apprenticeship programs will expire. Thus, states must monitor these programs to ensure they have the necessary funding to be successful. As is done in California, the CECAP must promote private partnerships with local communities to support those displaced from fossilfuel jobs or who struggle to enter the new clean energy industry (Luke 2017). As companies diversify their workforces through CECAP, they will be eligible to benefit from tax incentives.

iii. Recommendation 3: Establish a minimum resource investment requirement to support efficiency and clean energy projects with direct benefits for DACs

Clean energy technologies have high upfront costs that require governments to provide financial incentives to promote deployment in DACs (Carley and Konisky 2020; Mullendore 2019). We recommend states commit a minimum percentage of all funding for energy projects to proposals with direct benefits for DACs to meet this financial need. This strategy is modeled after policies adopted across the U.S. (Table A2). This policy would include existing and future programs, such as renewable generation, energy efficiency upgrades, and electrifying transportation. The commitment would also apply to all funds, including carbon pricing or cap-and-trade revenue, utility investments, and international financing. Direct benefits include good-paying jobs, lower electricity costs, and improved air quality, energy resilience, and mobility (Carley and Konisky 2020).

A minimum investment requirement incentivizes project developers to implement clean energy solutions within DACs as the money is designated only for these efforts. A broad commitment to funding for DACs reduces barriers to access because variability between programs disincentivizes individuals from applying. As the energy transition continues and agencies develop new programs, this policy directs new programs to be designed to support DACs from the start. Additionally, a broad commitment provides flexibility to meet each community's needs despite variability due to the location or building design.

However, funding streams may expire, decreasing the overall budget available to meet the needs of DACs. The minimum investment requirement may need to be revised upward to address this challenge. Additionally, agencies must conduct outreach and establish progress milestones for reducing the energy burden on DACs because these communities may not apply for grants solely because the money is available (Kupšys 2020). Targeted information campaigns have demonstrated success in California's EPIC program, which committed $65 \%$ of its funds to projects in DACs and low-income communities through Dec. 2019 (Doughman 2019).

\section{Conclusions and outlook}

We identified a "clean energy equity toolkit" to promote an equitable clean energy transition away from fossil-fuel energy sources for U.S. state governments interested in proactively tackling energy injustices. We encourage states to tailor these recommendations to best fit their goals and resource availability. Investment commitments and job training programs will support workers and prevent DACs from facing undue high energy costs. The Clean Energy Equity Office (CEEO) will streamline program eligibility and design, connect communities with relevant state programs, and evaluate progress towards clean energy access for all. A centralized CEEO also addresses some of the challenges faced by an investment commitment or a jobs program via outreach, program assessment, and funding tracking, enhancing the impacts of each of these policies.

Although these recommendations are based on and geared towards U.S. state governments, this toolkit can be adapted to any government prepared to tackle energy inequities. For example, the European Commission has directed Member States to allocate an unspecified amount of public funds towards lowincome households, which is analogous to the minimum investment requirement presented here (European Commission 2020). Adoption of these 
programs will ensure that historically DACs are supported during the transition from fossil-fuel based energy sources to clean sources and will reap important energy, cost, and job benefits unlike those historically offered to them.

\section{Appendix}

\begin{tabular}{|c|c|c|}
\hline Government & Initiative & Reference \\
\hline Virginia, USA & $\begin{array}{l}\text { Utilities must prioritize the hiring, apprenticeship, and } \\
\text { training of local workers and workers from historically } \\
\text { economically DACs, and must consider how job training } \\
\text { programs and energy facilities impact these communities. }\end{array}$ & S $851^{1}$ \\
\hline Washington, USA & $\begin{array}{l}\text { Establishes tiers of state tax incentives for energy } \\
\text { companies, certified by the Department of Labor and } \\
\text { Industries, contingent upon criteria such as priority hiring } \\
\text { and contracts with women, minority, or veteran-owned } \\
\text { businesses, compensating workers at prevailing wage rates, } \\
\text { and developing a community workforce or project labor } \\
\text { agreements }\end{array}$ & SB $5116^{2}$ \\
\hline California, USA & $\begin{array}{l}\text { Existing law supports state-approved apprenticeship } \\
\text { programs across sectors, primarily funded by private } \\
\text { companies, but subsidized by state funding. The state } \\
\text { includes "targeted hire" provisions in agreements with } \\
\text { contractors to encourage the hiring of members of targeted } \\
\text { groups (e.g. local residents, disadvantaged communities). } \\
\text { Apprenticeships are paired with local educational partners } \\
\text { to promote career advancement for those without advanced } \\
\text { formal training. The apprenticeship program is applicable } \\
\text { across sectors, but is emphasized in the energy sector via } \\
\text { policies such as the Renewables Portfolio Standard. }\end{array}$ & $\begin{array}{l}\text { UC Berkeley Labor } \\
\text { Center: Green } \\
\text { Economy Program } \\
\text { Shelly-Maloney } \\
\text { Apprentice Labor } \\
\text { Standards act of } \\
1939^{4}\end{array}$ \\
\hline New Jersey, USA & $\begin{array}{l}\text { Develop a grant program for community-based, diversity- } \\
\text { focused nonprofits to develop clean energy paid workforce } \\
\text { training programs that provide training to at least } 2,500 \\
\text { individuals from overburdened communities by } 2025 \text {. }\end{array}$ & SENATE, No. 24845 \\
\hline
\end{tabular}

Table A1: Existing state-funded programs for promoting equity in the clean energy workforce 


\begin{tabular}{|l|l|l|}
\hline Government & Investment Commitment & Reference \\
\hline Virginia, USA & $\begin{array}{l}\text { Utilities must make “deficiency payments" for not meeting } \\
\text { renewables portfolio standard requirements. 80\% of revenue } \\
\text { (administered through the Department of Mines, Minerals and } \\
\text { Energy) will be used for job training and renewable energy programs } \\
\text { directly benefiting historically economically disadvantaged groups. }\end{array}$ & S 8511 \\
\hline $\begin{array}{l}\text { New York, } \\
\text { USA }\end{array}$ & $\begin{array}{l}\text { 35-40\% of benefits of spending must be received by historically } \\
\text { DACs. This spending is distributed through state agencies in } \\
\text { consultation with both an Environmental Working Group and a } \\
\text { Climate Action Council. }\end{array}$ & CLCPA § 75-01176 \\
\hline $\begin{array}{l}\text { California, } \\
\text { USA }\end{array}$ & $\begin{array}{l}\text { 35\% of the Electric Program Investment Charge fund (administered } \\
\text { through the California Energy Commission and investor-owned } \\
\text { utilities) must go to projects located within and benefiting } \\
\text { individuals in DACs and low-income communities. }\end{array}$ & AB 5237 \\
\hline
\end{tabular}

Table A2: Existing state policies that make percentage-based clean energy investment commitments towards DACs.

${ }^{1} \mathrm{~S} 851$ 2020, ${ }^{2}$ SB5116 2019-2020, ${ }^{3}$ Luke et al. 2017, ${ }^{4}$ Shelly-Maloney Apprentice Labor Standards act of 19392005 , 5Senate No. 2484 2020, 6S. 6599 2019, ${ }^{\text {EEng et al. } 2018 .}$

\section{References}

S 851, Virginia Clean Economy Act, Chapter 1194, (VA 2020).

SB 5116, Supporting Washington's clean energy economy and transitioning to a clean, affordable, and reliable energy future, (WA 2019-2020). https://app.leg.wa.gov/billsummary?BillNumber $=5116 \&$ Initiative $=$ false \&Year $=2019$.

S. 6599, Article 75-0117, Climate Change: Investment of Funds, NY State Assembly, (NY 2019). https://legislation.nysenate.gov/pdf/bills/2019/ $\underline{\mathrm{s} 6599}$.

Ayub, Parwana and Sona Mohnot, Building a Diverse, Equitable, and Inclusive Cleantech Industry. The Greenlining Institute, 2020. https://greenlining.org/wpcontent/uploads/2020/12/Greenlining-BuildingDiverserse-Equitable-Inclusive-CleanTechIndustry-Report-2020.pdf.

Berube, Alan, Three things that matter for upward mobility in the labor market. The Brookings Institution, 2019. https://www.brookings.edu/blog/theavenue/2019/01/15/three-things-that-matterfor-upward-mobility-in-the-labor-market/.

California Public Utilities Commission (CPUC). 2019. "Decision Establishing a Self-Generation Incentive Program Equity Resiliency Budget, Modifying Existing Equity Budget Incentives, Approving Carry-Over of Accumulated Unspent Funds, and Approving \$10 Million to Support the San Joaquin Valley Disadvantaged Community Pilot Programs."
California Public Utilities Commission (CPUC). n.d.a "Disadvantaged Communities." Accessed $\begin{array}{lll}\text { November } & 2020 .\end{array}$ https://www.cpuc.ca.gov/discom/.

California Public Utilities Commission (CPUC). n.d.b "SelfGeneration Incentive Program." Accessed November 20, 2020. https://www.cpuc.ca.gov/sgip/.

California Public Utilities Commission (CPUC). 2021. "Clean Energy Financing Workshop for R.20-08022" Accessed February 28, 2020. http://www.adminmonitor.com/ca/cpuc/works hop/20210128/.

Carley, Sanya and David M Konisky. 2020. "The Justice and Equity Implications of the Clean Energy Transition" Nature Energy 5 (June): 569-577 https://doi.org/10.1038/s41560-020-0641-6.

Doughman, Pamela, Electric Program Investment Charge 2019 Annual Report. 2020. https://ww2.energy.ca.gov/2020publications/CE C-500-2020-009/CEC-500-2020-009-CMF.pdf.

ENERGY STAR. 2012. "Building Performance with ENERGY STAR Program Framework ," January 2012. https://www.energystar.gov/sites/default/files/ asset/document/BPwES Program_Framework Website.pdf.

Eng, Tiffany et al. CalEnviroScreen: A Critical Tool for Achieving Environmental Justice in California. California Environmental Justice Alliance, 2018. https://leginfo.legislature.ca.gov/faces/billTextCl ient.xhtml?bill id=201720180AB523. 
Environmental Protection Agency. "Chumash Community Energy Efficiency and Renewable Energy Project." June 2016. https://www.epa.gov/sites/production/files/20 $\underline{17-}$

$\underline{06 / d o c u m e n t s / c h u m a s h ~ c o m m u n i t y ~ e n e r g y ~ e f f i ~}$ ciency and renewable energy project profile .pd f.

Environmental Protection Agency. "Environmental Justice." 2016. https://www.epa.gov/environmentaljustice.

European Commission, Commission Recommendation of 14.10.2020 on energy poverty, Kadri Simson. Brussels, $\quad$ Belgium: 2020. https://ec.europa.eu/energy/sites/ener/files/re commendation on energy poverty c2020 9600. pdf.

Foster, David. Rep. 2020 U.S. Energy \& Employment Report. National Association of State Energy Officials and Energy Futures Initiative, n.d. https://static1.squarespace.com/static/5a98cf80 ec4eb7c5cd928c61/t/5ee78423c6fcc20e01b838 96/1592230956175/USEER+2020+0615.pdf.

Graff, Michelle, and Maureen Pirog. "Red tape is not so hot: Asset tests impact participation in the LowIncome Home Energy Assistance Program." Energy Policy 129 (2019): 749-764. https://doi.org/10.1016/i.enpol.2019.02.042.

Griffith, Alden B., Monica R. Higgins, and James Morton Turner. 2014. "A rooftop revolution? A multidisciplinary analysis of state-level residential solar programs in New Jersey and Massachusetts." Journal of Environmental Studies and Sciences 4, no. 2 (2014): 163-171. https://doi.org/10.1007/s13412-013-0156-6

Kann, Shayle, and Attila Toth. "How Wealthy Are Residential Solar Customers?" 2017. gtmresearch .

Kupšys, Kęstutis. 2020. "Policy Recommendations for the Implementation of the Clean Energy for all Europeans Package" Solutions to Tackle Energy Poverty: STEP Project.. https://www.stepenergy.eu/wpcontent/uploads/2020/08/Policy Recommendat ions 1st set D6.3 final.pdf.

Langer, Gary. 2018. "Public Backs Action on Global Warming -but with Cost Concerns and Muted Urgency." ABC News/Stanford/Resources for the Future Poll: Public Attitudes on Global Warming. Langer Research Associates. https://www.langerresearch.com/wpcontent/uploads/1198a1Global-Warming.pdf.

Lukanov, Boris R., and Elena M. Krieger. 2019.

"Distributed solar and environmental justice:

Exploring the demographic and socio-economic trends of residential PV adoption in California."

Energy Policy 134 (2019): 110935

https://doi.org/10.1016/i.enpol.2019.110935

Luke, Nikki, Carol Zabin, Dalia Velasco, and Robert Collier. Rep. Diversity in California's Clean Energy Workforce: Access to Jobs for Disadvantaged Workers in Renewable Energy Construction, August 2017.

Mullendore, Seth. 2019. "Energy Storage Is Failing to Reach Those Most in Need: Policy Can Help." Renewable Energy World, November 22, 2019. https://www.renewableenergyworld.com/2019/ 11/22/energy-storage-is-failing-to-reach-thosemost-in-need-policy-can-help/.

New Jersey Legislature. Senate. No. 2484. 219th Legislature., Introduced in Senate May 14, 2020. https://www.njleg.state.nj.us/2020/Bills/S2500 $\angle 2484$ I1.PDF.

Penn State College of Agricultural Sciences. n.d. "Why Community Engagement Matters." Plone site. Accessed December 15, 2020.

https://aese.psu.edu/research/centers/cecd/eng agement-toolbox/engagement/why-communityengagement-matters.

Senate No. 2484, 219th Legislature, Office of Clean Energy Equity, (NJ 2020).

https://www.njleg.state.nj.us/2020/Bills/S2500 22484 I1.PDF

Shelly-Maloney Apprentice Labor Standards act of 1939, California Labor Code Sections 3070-3099.5 (2005), Chapter 4. Apprenticeship. https://law.justia.com/codes/california/2005/la b/3070-3099.5.html

Sunter, Deborah A., Sergio Castellanos, and Daniel M. Kammen. 2019. "Disparities in rooftop photovoltaics deployment in the United States by race and ethnicity." Nature Sustainability 2, no. 1 (2019): 71-76. https://doi.org/10.1038/s41893018-0204-Z

Vachon, Todd E. 2019. "The Green Transition: Renewable Energy Technology, Climate Change Mitigation, and the Future of Work in New Jersey."

Zhai, Panmao, Hans-Otto Pörtner, Debra Roberts, J. Skea, P. R. Shukla, Anna Pirani, W. Moufouma-Okia, C. Péan, R. Pidcock, and S. Connors. 2018. "Global Warming of 1.5 OC: An IPCC Special Report on the Impacts of Global Warming of $1.5^{\circ} \mathrm{C}$ Above Preindustrial Levels and Related Global Greenhouse Gas Emission Pathways, in the Context of Strengthening the Global Response to the Threat of Climate Change, Sustainable Development, and Efforts to Eradicate Poverty. 
Sindhu Nathan is a PhD candidate in chemical engineering at Stanford University. She researches catalyst materials used for converting syngas (carbon monoxide and hydrogen) to value-added products such as ethanol or other chemical feedstocks. In addition to her research, she is a former Shultz Fellow at the California Energy Commission in the Office of Commissioner Patty Monahan. She is also the Vice-President of the Stanford Science Policy Group, Vice-Chair of Communications at the National Science Policy Network, and an active member of the Diversity, Equity, and Inclusion Committee in the same organization.

Kavitha Chintam is a PhD student studying chemical engineering at Northwestern University. Her research focuses on co-electroreduction of carbon dioxide with additives and the process's underlying mechanisms. Kavitha is the Legislative Outreach Chair for Northwestern's Science Policy Outreach Taskforce (SPOT) and heads the Science One-Pager Initiative. She is also an active member of her department's anti-racism, diversity, equity, and inclusion committee. Outside of Northwestern, she is a volunteer with refugee organizations in Chicago and environmental justice groups in the Midwestern U.S. She is a member of the National Science Policy Network.

Brooks Clingman is a graduate student studying Materials Science and Engineering at the Massachusetts Institute of Technology. His research focuses on overcoming barriers to manufacturing scalability for lithiumion batteries and future battery chemistries. Brooks is keenly interested in energy technology and the clean energy transition, and he aims to facilitate technology transfer of promising early-stage energy technologies throughout his career. Prior to graduate school, Brooks worked in the private sector for an aerospace and defense contractor. He is a member of the National Science Policy Network.

Alexandra Johnson is a Master of Public Health student at the University of California, Berkeley and a research associate at Lawrence Berkeley National Lab. Her research focuses on indoor air quality. Alexandra has multiple years of experience working with groups at the volunteer level lobbying for clean energy and environmental health, and previously worked as an environmental engineer in both the public and private sectors after obtaining her undergraduate degree in chemical engineering. She is currently a member of the National Science Policy Network and works with various environmental justice groups in California, with a focus on policy.

\section{Acknowledgements}

The authors would like to thank the members of the National Science Policy Network for their edits and feedback during the development of the memo.

\section{Disclaimer}

Authors' views do not necessarily reflect those of their respective departments or institutions. 